EESTI NSV TEADUSTE AKADEEMIA TOIMETISED. XIV KÖDE

FOOSIKA-MATEMAATIKA- JA TEHNIKATEADUSTE SEERIA. 1965, NR. 3

ИЗВЕСТИЯ АКАДЕМИИ НАУК ЭСТОНСКОИ ССР. ТОМ ХІV

СЕРИЯ ФИЗИКО-МАТЕМАТИЧЕСКИХ И ТЕХНИЧЕСКИХ НАУК. 1965. № 3

Х. ЛАУЛ

\title{
О РАЗВИТИИ ТЕОРИИ ТОНКОСТЕННЫХ КОНСТРУКЦИЙ В ЭСТОНСКОЙ ССР
}

Развитие теории и методов расчета тонкостенных конструкций в Эстонской ССР началось после войны в 1945 г., когда Н. Алумяэ, защитив кандидатскую диссертацию, вернулся в Таллинский политехнический институт после трехлетней работы в Академии наук Украинской ССР. К научной работе в области теории тонкостенных конструкций он привлек ряд своих коллег и студентов. Поэтому теперь, накануне 50-летия Н. Алумяэ, весьма уместно попытаться подвести итоги двадцатилетней работы в области развития теории тонкостенных конструкций в нашей республике. Выполняя приятное поручение коллег и учеников Н. Алумяэ, автор задался целью коротко осветить следующие разделы:

1. Теория упругой и пластической устойчивости и равновесия оболочек и пластинок; анализ точности теорий.

2. Динамика оболочек и плит; анализ точности инженерных теорий динамики.

3. Экспериментальное исследование при статических нагрузках.

1. Теория статической устойчивости и равновесия оболочек. Проблемы статической устойчивости тонких упругих оболочек длительное время служили предметом исследований Н. Алумяэ. В своих работах $[1,2,7]$ он вывел основные соотношения общей нелинейной теории оболочек в тензорной записи с выделением чистой деформации и конечного поворота элемента. В этих же работах им установлены пределы применимости упрощенной теории напряженных состояний с большим показателем изменяемости для изучения работы оболочки в послекритической стадии равновесия. Указанные работы определили строгую основу нелинейной теории оболочек в пределах точности гипотез Кирхгоффа-Лява, практически всегда оправданных в задачах устойчивости тонких оболочек. В статьях $[3-7,9]$ Н. Алумяэ развивал методы приближенного решения нелинейных задач теории оболочек. Были предложены новые вариационные формулы (типа Кастильяно и смешанного типа) с разным набором допустимых функций, позволяющие значительно расширить сферу применения приближенных методов; рассматривались также применение метода малого параметра и другие вопросы.

Используя развитые им строго обоснованные уравнения и вариацнонные формулы общего характера, Н. Алумяэ приступил к систематическому анализу проблем устойчивости конкретных видов оболочек $[8,10-13,16,17,20,21]$ : были исследованы цилиндрические, конические, катеноидные, эллипсоидальные и геликоидальные оболочки. В то же время Н. Алумяэ продолжал усовершенствование основ общей теории $[14,15,19]$. Однако наибольшей заслугой Н. Алумяэ является внедрение им в нелинейную теорию метода расчленения напряженных состояний $[8,11,13,16,17,20,21]$. Дело в том, что в случае задач, приводящих к дифференциальным уравнениям с переменными коэффициентами и малым параметром при старших производных, основную трудность при разработке эффективных расчетных методов представляют изучение асимптотических свойств решений и построение соответствующих асимптотических формул. В указанных работах Н. Алумяэ применил для этой цели различные видоизменения асимпто- 
тического (ВКБ) метода. Следует отметить, что ряд исследований доведен им до численных результатов.

В области нелинейной теории успешно работали также коллеги и ученики Н. Алумяэ: Л. Айнола, Ю. Ааре, К. Оллик, У. Нигул, Л. Поверус, Р. Ряямет и П. Мюрсепп.

Л. Айнола дал обобщение вариационных методов в нелинейной теории упругих оболочек $[18,22]$. Ю. Ааре $\left[{ }^{23}\right]$ исследовал устойчивость плит, работающих в условиях сдвига (панель стенки металлической балки). Л. Поверус $[24,25]$ изучал состояние равновесия в послекритической стадии упругой оболочки вращения (малой положительной кривизны), находящейся под действием равномерного давления. Р. Ряямет $[26,27]$ занимался вопросами критических нагрузок и послекритического равновесия конической оболочки. К. Оллик $\left.{ }^{29}\right]$ рассматривал поведение круговой цилиндрической оболочки при больших внешних боковых давлениях. У. Нигул дал энергетическую формулировку теории тонкостенных стержней [32]. П. Мюрсепп исследовал устойчивость равновесия цилиндрических и конических оболочек под внешним давлением [33, 34, 35].

В некотором смысле итоговой для этого периода исследований явилась обзорная статья Н. Алумяэ [28], опубликованная в 1958 г. После этого он, как и ряд его коллег, переключился на изучение вопросов динамики.

Следует, однако, отметить, что Ю. Ааре в Таллинском политехническом институте гродолжал исследование проблем устойчивости краевых панелей металлических балок $[30,31]$. Последние результаты его работы представлены в отдельной статье данного выпуска. Расчет современных металлических балок (в частности мостовых) приходится выполнять с учетом послекритической стадии деформации крайних панелей вертикальной стенки, работающих в контакте с деформируемыми ребрами и поясами балки. Отсюда вытекает довольно сложная задача анализа послекритической стадии работы плиты в условиях деформации окаймляющей конструкции. Ю. Ааре атаковал эту задачу энергетическим методом (задаются перемещения) и, пользуясь услугами вычислительного центра Института кибернетики АН ЭССР, получил обширную численную информацию, позволяющую дать обоснованные указания проектировщикам. Заслуживают внимания и экспериментальные исследования Ю. Ааре, подтверждающие результаты его теоретического исследования и подчеркивающие важную роль конструкции опорных ребер жесткости, определяющих предел общей устойчивости балки.

Развитию теории устойчивости систем, находящихся в пластическом напряженном состоянии, предложенной А. А. Ильюшиным в 1944 г., большое внимание уделили Ю. Лепик и его сотрудники. В работах Ю. Лепика [36-38] исследуется влияние сжимаемости материала на критическую нагрузку пластинок; в его статьях $[41,45]$ при помощи точного решения некоторых задач устойчивости проверяется гипотеза А. А. Ильюшина (предполагается, что толщина пластического слоя по всей выпученной пластинке постоянна). На основе названной теории Ю. Лепик исследовал устойчивость неравномерно сжатой прямоугольной пластинки [43].

В стадии упруго-пластических деформаций критические нагрузки для пластинок различных форм (треугольник, трапеция, параллелограмма, сектор кольца) вычислил Л. Роотс [51, 52].

Теория А. А. Ильюшина предполагает, что потеря устойчивости происходит при постоянной внешней нагрузке. В 1947 г. Шэнли показал, что возможна потеря устойчивости также при увеличивающейся нагрузке. Этому же вопросу посвятил свои статьи Ю. Лепик [39, 48, 49].

Теория гибких упруго-пластических пластинок нелинейна как геометрически, так и физически. Для нахождения приближенных решений Ю. Лепик предложил соответствующую расчетную схему [44].

В его же работах даются решения для задачи поперечного и поперечно-продольного изгиба симметрично нагруженных круглых пластинок с защемленными краями $\left[{ }^{42}\right]$, приводится решение задачи поперечного изгиба свободно опертой круглой пластинки [5], осуществленное при помощи электронной вычислительной машины, представляются формулы для расчета необратимой части прогибов и напряжений в упруго-пластической пластинке [ $\left.{ }^{4}\right]$. 
При оценке несущей способности пластинок и оболочек часто пренебрегают влнянием упругих деформаций и считают материал идеально пластичным. Ю. Лепик попытался дать решение для гибких круглых и кольцевых пластинок [47].

Некоторые работы были посвящены исследованию точности основных положений теории оболочек и плит.

У. Нигул в своих работах $[54,55]$ исследовал точность теории Кирхгоффа-Лява в случае круговых цилиндрических оболочек: методом степенных рядов были получены асимптотические при $a \rightarrow 0$ ( $a-$ относительная толщина оболочки) уравнения и формулы для перемещений, моментов и усилий. Было установлено, что наиболее удачным вариантом теории Кирхгоффа-Лява является простейший вариант В. В. Новожилова, при котором погрешности теории Қирхгоффа-Лява взаимно компенсируются.

У. Нигул на основе теории упругости провел асимптотический анализ при $a \rightarrow 0$ (здесь $a$ - отношение толщины к пролету) и численный анализ точности теории Кирхгоффа в случае задачи изгиба защемленной плиты $\left[{ }^{56,57]}\right.$. Было установлено, что разложения по степеням параметра $a$ имеют существенно различные коэффициенты, и поэтому асимптотические оценки [56] точности теории Кирхгоффа следует применять с некоторой осторожностью.

Л. Айнола представил обобщение уточненной теории типа Рейсснера, в которой задается закон изменения напряжений $\sigma^{\alpha \beta}(\alpha, \beta=1,2)$ по толщине плиты [58]. Л. Айнола задавал $\sigma^{\alpha \beta}$ через искомую функцию $\psi(z)$, которая определяется в ходе решения задачи. Используя вариационный принцип, он ввел систему интегро-дифференциальных уравнений, состоящую йз уравнений плиты типа Рейсснера и из дополнительного уравнения для определения $\psi(z)$.

2. Динамика оболочек и плит и анализ точности инженерных теорий динамики. Исследование проблем динамики плит и оболочек началось в Эстонии сравнительно недавно - примерно в 1958 г. Вначале основное внимание было сосредоточено на изучении малых собственных колебаний на основе линейной теории Кирхгоффа-Лява. K. Оллик [59] исследовал формы и частоты осесимметричных колебаний круговых цилиндрических оболочек и составил соответствующие таблицы. Л. Поверус и Р. Ряямет [60] изучали первые формы неосесимметричных собственных колебаний усеченных конических и цилиндрических оболочек. Был применен энергетический мегод; основное внимание уделялось определению первой собственной частоты, которая в зависимости от относительной толщины и длины оболочки имеет место при различных числах циклической симметрин. У. Нигул [61, 62] провел качественный и численный анализы уравнений циклосимметричных собственных колебаний круговой цилиндри. ческой оболочки в весьма широкой области изменения параметров

$$
0<N \leqslant a^{-1}, \quad 0<n \leqslant a^{-\frac{3}{4}}
$$

где

$$
N=\frac{\left(1-v^{2}\right) R^{2} \varrho \omega^{2}}{E}, \quad a=\frac{h}{\sqrt{12} R},
$$

$n$ - число циклической симметрии (волн по окружности), $h, R$ - толщина и радиус оболочки.

Область (1) была разбита на отдельные части, для которых даны обоснованные приближенные в асимптотическом смысле уравнения [61]. В частности, были выявлены области применимости безмоментной и полубезмоментной теорий, теории простых краєвых эффектов и теории с большим показателем изменяемости. В работе [62] представлены диаграммы линий равного уровня корней характеристического уравнения на плоскости $N, n$. Расчленение напряженного состояния на элементарные, описываемые более простыми уравнениями, удалось везде, за исключением некоторой области, где $N \approx 1$. 
Нанболее важной на этапе исследования собственных колебаний является работа [63], которую Н. Алумяэ посвятил весьма сложной проблеме построения фундаментальняй системы интегралов уравнения малых осесимметричных установившихся колебаний конической оболочки вращения. Указанная задача описывается обыкновенными цифференциальными уравнениями, имеющими переменные коэффициенты, зависящие от частоты. Сложность задачи - в наличии точки разветвления решений, где уравнения, не учитывающие затухание, дают бесконечное решение, а уравнения, учитывающие затухание, определяют быстро изменяющееся напряженное состояние, которое не поддается построению простыми стандартными приемами, ибо у точки разветвлення имеет место качественное изменение интегралов (например, краевые эффекты вырождаются). Н. Алумяэ построил решения для диапазона частот в окрестности точки разветвления при помощи эталонного уравнения путем тонкого анализа решений последнего, найденных в виде контурных интегралов.

С работой [63] тесно связана статья [64], дополняющая первую численными примерами для осесимметричного колебания усеченной конической оболочки.

C проблематикой собственных колебаний связана также несколько более поздняя работа Л. Айнола [65], в которой методом неполного разделения переменных дано обоснование (и некоторое обобщение) асимптотического метода В. В. Болотина для определения собственных частот колебания плит при краевых условиях, не допускающих применения метода Навье.

У. Нигул исследовал [66] колебание круговой цилиндрической оболочки, вызванное действием сосредоточенного нормального и наклонного импульсов. Им был использован метод Фурье и получено большое количество диаграмм. Оказалось, что практически приходится брать тем больше членов в рядах, чем меньше относительная толщина объекта и короче длительность нагрузки. Указанное привело к выводу, что при весьма кратковременных или быстрорастущих нагрузках необходимо применять концепцию бегущих волн. Но поскольку система уравнений теории Кирхгоффа-Лява параболическая, выросла, в свою очередь, проблема подбора расчетных моделей (уравнений) для анализа переходных волновых процессов деформации плит и оболочек. Эти вопросы и стали предметом дальнейших исследований.

Н. Алумяэ [67] на базе теории типа Тимошенко рассматривал переходный волновой процесс деформации полубесконечной круговой цилиндрической оболочки, вызванный действием импульсной тангенциальной краевой нагрузки, изменяющейся во времени по синусоидальному закону. Исследование проведено при помощи преобразования Лапласа по времени. При этом изображения были детально проанализированы, что позволило выяснить точки разветвления отдельных корней характеристического уравнения и изображений в целом, а также провести обращение контурных интегралов методом перевала. Фактически эта работа является первой серьезной попыткой внедрить в теорию переходных волновых процессов деформации оболочек метод расчленения напряженных состояний, успешно использованный Н. Алумяэ ранее в задачах устойчивости. С этой же целью рассматривалась $\left[{ }^{68}\right]$ задача об определении осевых напряжений в полубесконечной круговой цилиндрической оболочке, вызванных действием внезапно приложенной циклосимметричной краевой нагрузки. Наряду с методом перевала в работе [68] (по-видимому, впервые в динамике плит и оболочек) применялся метод обращения контурных интегралов преобразования Лапласа, основывающийся на аппроксимации изображения на равноотстоящих точках вещественной оси плоскости комплексного параметра преобразования.

Было установлено [67, 68], что при тангенциальных нагрузках, приложенных к неасимптотическому краю и изменяющихся по нему достаточно медленно, в общем удается расчленить напряженное состояние на медленно изменяющееся (безмоментное или полубезмоментное) и быстро изменяющиеся (квазистатические простые краевые эффекты) решения, хотя следует отметить, что зона $N \sim 1$ (см. формулу (2)) заслуживает некоторого дальнейшего исследования.

Используя опыт указанных работ, А. Тюманок [69] на базе безмоментной теории исследовал колебание круговой цилиндрической оболочки под действием волны равно- 
мерного нормального давления, движущейся с постоянной скоростью вдоль оси оболочки. Здесь заслуживает внимания способ группового обхода особых точек, использованный для обоснования приближенных формул обращения контурных интегралов преобразования Лапласа, а также применение метода характеристик. Отметим, что в данном номере журнала публикуется работа А. Тюманока $\left[{ }^{70}\right]$, в которой эта же задача исследована на базе теорин типа Тимошенко. Қак можно было ожидать, поправки к безмоментной теории существенны лишь в весьма узких диапазонах.

У. Нигул занимался проблемами анализа точности инженерных теорий. На основе трехмерной теории упругости он вывел $\left.{ }^{[54}\right]$ уравнения динамики круговых цилиндрических оболочек восьмого и десятого порядков, имеющие, соответственно, асимптотические погрешности порядка $\theta_{0}=a^{2}\left(1+\lambda^{2}\right)$ и $\theta_{1}=a^{2}\left(1+a^{2} \lambda^{4}\right)$ (здесь $\lambda-$ наибольший из показателей изменяемости по координатам и времени). У. Нигул дал также [71] асимптотические расчетные формулы для динамических перемещений, усилий и других искомых величин, выраженных через одну разрешающую функцию. Далее он приступил к анализу переходных волновых процессов на основе трехмерной теории упругости. Вначале были проведены исследования подготовительного характера: дано обобщение символического метода А. И. Лурье для динамики плит [72]; исследованы корни уравнения Релея-Лэмба [73], изучено распределение перемещений и напряжений трех первых мод по толщине плиты и приведены численные данные о точности гипотез, применяемых в инженерных теориях [74]. Далее он исследовал [75, 76] на конкретных примерах переходные волновые процессы деформации плит. Были установлены области обоснованной применимости инженерных теорий и развиты методы для тех областей плоскости $\alpha, t$ ( $\alpha$ - кордината срединной поверхности, $t-$ время), где инженерные теории не применимы. Подробный отчет об этих исследованиях, в том числе о методе трехмерных сеток, представлен в настоящем выпуске (см. статью У. Нигула). Необходимо отметить, что $\mathrm{y}$. Нигул широко применяет новую вычислительную технику и пропагандирует ее среди свонх коллег. Об этом свидетельствуют коллективные работы [77-79], посвященные применению усовершенствованного варианта метода сеток для анализа (на базе теорни типа Тимошенко) волновых процессов деформации плит и сферической оболочки. Программа алгоритма для метода трехмерных сеток дана в статье А. Мянниль, помещенной в настоящем выпуске. Следует отметить большой труд математиков-программистов А. Мянниль и М. Петерсон. А. Мянниль запрограммировала примеры, опубликованные в ряде статей [ $\left.{ }^{69},{ }^{73-78}\right]$, а $М$. Петерсон - примеры для трех статей $[67,68,79]$. Кроме того, М. Петерсон выполнила под руководством Н. Алумяэ многочисленные расчеты в связи с внедрением теоретических результатов ь практику проектирования.

Теоретическими проблемами занимается Л. Айнола. Он дал обобщение вариа. ционного метода Кастильяно для динамической нелинейной теории упругости [80], предложил вариационный метод приближенного решения дифференциальных уравнений с частными производными [ $\left.{ }^{81}\right]$, являющийся обобщением известных методов Ритца и Канторовича. По предлагаемому методу решение получается в виде ряда из произведений двух искомых-сомножителей, из которых каждый является функцией только одной переменной. Л. Айнола рассматривал также проблему уточнения теории плит и вывел [82] вариационным методом в общей форме теорию, являющуюся обобщением известных жуточненных» теорий типа Тимошенко и Кейна-Миндлина. В данном выпуске Л. Айнола выступает с нелинейной теорией типа Тимошенко для произвольных оболочек.

Большой интерес представляет недавно опубликованная обзорная статья Л. Айнола и У. Нигула [ $\left.{ }^{33}\right]$.

3. Экспериментальные исследования при статических нагрузках и приближенные методы расчета железобетонных оболочек. Возможности применения метода фотоупругости для определения напряженного состояния гибких плит и оболочек (после выпучивания) при помощи сквозного просвечивания моделей по нормали к поверхности рассматривали X. Абен и Э. Сакс [84, 85]. Специфика рассматриваемой задачи состоит 
в том, что в направлении светового луча изменяется напряженное состояние и вследствие этого также оптическая анизотропня. Х. Абен и Э. Сакс доказали, что при просвечивании оболочки всегда существует такое положение поляризаторов, при котором выходящий свет также является линейно поляризованным. Указанные направления и фазовый сдвиг в этих направлениях определяются экспериментальным путем. На основе экспериментальных данных напряженное состояние определяется при помощи уравнений фотоупругости рассматриваемой задачи (составленных на основе уравнений Максвелла), решение которых дано для оптически малочувствительных материалов.

Впоследствии этот метод применялся при исследовании оболочек методом фотоупругих покрытий [86] и для определения напряжений в оболочках вращения при помощи тангенциального просвечивания [87]. Кроме указанных, Х. Абеном выполнено большое количество работ, посвященных теоретическим вопросам метода фотоупругости.

Начиная с 1947 г. в Эстонской ССР проводятся исследования железобетонных оболочек. Проведены испытания примерно на 40 моделях оболочек разного вида из армоцемента и предложены новые инженерные методы расчета железобетонных оболочек. Результаты этих исследований излагаются в специальной статье автора, также помещенной в настоящем номере журнала.

В пределах данного обзора удалось лишь весьма бегло и неполно отразить плодстворную деятельность Ю. Лепика и ряда молодых ученых, воспитанных им в Тартуском государственном университете. Поэтому обращаем внимание читателей на специальную обзорную статью Ю. Лепика [88].

\section{ЛИТЕРАТ У РА}

1. Алумяэ Н., Равновесие тонкостенных упругих оболочек в послекритической стадии, Труды Таллинского политехнического ннститута. Серня А*, № 28 (1948).

2. Алум яэ Н., Дифференциальные уравнения состояний равновесия тонкостенных упругих оболочек в послекритической стадин, ПММ, 13, вып. 1 (1949),

3. А лум я э Н., К одной формуле критического напряжения безмоментного напряженного состояния тонкостенных упругих оболочек, ПММ, 13, вып. 6 (1949).

4. Алум яэ Н., Применение обобщенного вариационного принципа Кастильяно к исследованию послекритической стадии тонкостенных упругих оболочек, ПММ, 14, вып. 1 (1950).

5. Алумяэ Н., Одна вариационная формула для исследования тонкостенных упругих оболочек в послекритической стадин, ПММ, 14, вып. 2 (1950).

6. Ал ум яэ Н., Исследование послекритической стадии тонкостенных упругих оболочек методом разложения по степеням малого параметра, Сб. О развитии советской науки в Эстонской ССР, № 2, Таллин, 1950.

7. Алумяэ Н., К теории осесимметричной деформации оболочек вращения при конечных перемещениях ПММ, 16, вып. 4 (1952).

8. А лум яэ Н., О критическом значении осесимметричного безмоментного состояния длинной катеноидной оболочки, ПММ, 16, вып. 6 (1952).

9. А лум яэ Н., Вариационные формулы исследования гибких пластинок и оболочек, Сб. По расчету гибких пластин н оболочек, М., 1952.

10. Алумяэ Н., Об определении состояний равновесия круговой оболочки при осесимметричной нагрузке, ПММ, 17, вып. 5 (1953).

11. А лу м яэ Н., K определению критической нагрузки замкнутой к вершине конической оболочки вращения, находящейся под действием внешнего давлення, Тр. ТПИ, А, № 65 (1953).

12. А лум яэ $\mathrm{H}$., $\mathrm{K}$ определению состояний равновесия длинных цилиндрических оболочек вращения при осесимметричной нагрузке, Изв. АН ЭССР, 3 , № I (1954).

13. А лум я э Н., Критическая нагрузка длинной цилиндрической круговой оболочки при крученин, ПММ, 18, вып. 1 (1954).

14. Алумяэ Н., Об аналогии между геометрическими и статистическими соотношениями в нелинейной теории оболочек, Изв. АН ЭССР, 4, № 2 (1955).

15. Алу м яэ Н., О представлении основных соотношений нелинейной теории оболочек, ПММ, 20, вып. 1 (1956).

* В дальнейшем сокращенно - Тр. ТПИ, А. 
16. Алум яэ Н., Определение критического давления оболочки, очерченной по однополостному гиперболоиду, ПММ, 20, вып. 2 (1956).

17. Алумяэ Н., Критическое давление упругой оболочки вращения, очерченной по поверхности эллипсонда, Изв. АН ЭССР. Сер. техн. и физ.-матем. наук, 5, № 3 (1956).

18. А й нол а Л., О возможностях формулировки вариационной задачи в нелинейной теории упругих оболочек, Тр. ТПИ, А, № 104 (1957).

19. Алумяэ Н., Основные энергетические соотношения при деформации тонкостенных упругих оболочек, Сб. Исследования по вопросам устойчивости, М., 1956.

20. Алумяэ Н., Асимптотическое интегрирование уравнений статической устойчивости конической оболочки вращения, ПММ, 21, вып. 1 (1957).

21. Алум я $э$ Н., Устойчивость равновесия геликоидальной оболочки, ПММ, 21, вып. 6 (1957).

22. Айнола Л., Вариационные задачи в нелинейной теории упругих оболочек, ПММ, 21, вып. 3 (1957).

23. А а ре Н., Расчет гибких пластин при работе их на сдвиг, Тр. ТПИ, А, № 65 (1955).

24. Поверус Л., Устойчивость оболочки вращения с малой положительной кривизной под действием равномерно распределенного внешнего давления, Тр. ТПИ, А, № 65 (1955).

25. Поверус Л., Исследование состояний равновесия в послекритической стадии упругой оболочки вращения малой положительной кривнзны, находящейся под действием равномерно распределенного внешнего давления, Тр. ТПИ, А, № 82 (1956).

26. Р яямет Р., Критическая нагрузка конической оболочки, находящейся под действием равномерно распределенного внешнего давления, Тр. ТПИ, А, № 65 (1955).

27. Ряямет Р., Равновесие тонкостенных упругих конических оболочек в послекритической стадии, Тр. ТПИ, А, № 82 (1956).

28. Алумяэ Н., Лінійні задачі теоріі статичноі стійкості і власних коливань тонких пружних оболонок (огляд). Прикладна механіка, 3, вып. 1 (1958).

29. Оллик К., Устойчивость упругой круговой цилиндрической оболочки при больших внешних боковых давлениях, Тр. ТПИ, А, № 65 (1955).

30. А а ре И., О влиянии изгибной жесткости пояса тонкостенной балки на работу стенки, Тр. ТПИ, А, № 218 (1965).

31. А а ре И., Расчет гибких пластин при работе на сдвиг с учетом жесткости конгурных ребер на сжатие, Тр. ТПИ, А, № 218, 1965.

32. Н игул У., Энергетический вариант теории устойчивости тонкостенных упругих стержней, Тр. ТПИ, А, № 53 (1954).

33. Мюрсеп п П., Об устойчивости круговой цилиндрической оболочки под действием равномерно распределенного внешнего давления, Изв. АН ЭССР. Сер. техн. и физ.-матем. наук, 6, № 4 (1957).

34. М юрсеп п П., Об устойчивости кругового усеченного конуса под действием равномерно распределенного внешнего давления, Изв. АН ЭССР. Сер. техн. и физ.-матем. наук, 7, № 2 (1958).

35. М юрсеп п П., К определению критической нагрузки конической оболочки вращения, Тр. Ин-та физ, и астр. АН ЭССР, № 13 (1961).

36. Л п и К Ю., Два замечания к теории устойчивости пластинок за пределом упругости с учетом сжимаемости материала, ПІММ, 14, вып. 5 (1950).

37. Л п ик Ю., Дополнительные замечания о цилиндрической форме потери устойчивости пластинок за пределом упругости, ПММ, 15, вып. 1 (1951).

38. Л епи Ю., Потеря устойчивости пластинок из сжимаемого материала на площадке текучести, ПММ, 15, вып. 5 (1951).

39. Л епик Ю., Еще раз к вопросу о цилиндрической форме потери устойчивости упруго-пластических пластинок, ПММ, 20, вып. 1 (1956).

40. Лепик Ю., О равновесии сжатых упруго-пластических стержней, ПММ, 21, вып. 1 (1957).

41. Л пик Ю., Об устойчивости упруго-пластической прямоугольной пластинки, сжатой в одном направлении, ПММ, 21, вып. 5 (1957).

42. Лепик Ю., О равновесии гибких пластинок за пределом упругости, ПММ, 21, вып. 6 (1957).

43. Л е п к Ю., Устойчивость прямоугольной упруго-пластической пластинки, неравномерно сжатой в одном направлении, Инженерн. сб., 18 (1954).

44. Л е п к Ю., Равновесие гибких упруго-пластических пластинок при больших прогибах, Инженерн. сб., 24 (1956).

45. Лепик Ю., Одна возможность решения задачи об устойчивости упруго-пластических пластинок в точной постановке, Изв. АН СССР. Отд. техн. наук, № 8 (1957). 
46. Л п и к Ю., Определение остаточного прогиба и остаточных усилий при разгружении гибких упруго-пластических пластинок, Изв. АН СССР. ОТН. Отд. механ. и машнностр., № 3 (1959).

47. Л е пи К Ю., Пластическое течение гибких круглых пластинок из жестко-пластического материала, Изв. АН СССР. ОТН. Отд. механ. и машиностр., № 2 (1960).

48. Л еп к Ю., О влиянии начальной кривизны и эксцентричного нагружения на прогиб сжатого стержня за пределами упругости, Уч. зап. Тартуск. ун-та, вып. 62 (1958).

49. Лепик Ю., К исследованию послекритической стадии пластинок, потерявших устойчивость за пределом упругости, Уч. зап. Тартуск. ун-та, вып. 73 (1954).

50. Л е п к Ю., К исследованию послекритической стадии прямого упруго-пластического стержня, Уч. зап. Тартуск. ун-та, вып. 102 (1961).

51. Р оот с Л., Об устойчивости пластинок в форме сектора кольца при напряжениях, больших предела пропорциональности, Тр. Ин-та физ. и астрон. АН ЭССР, № 13 (1961).

52. Роотс Л., Об устойчивости пластинок различной формы, в частности треугольных и трапециевидных, Уч. зап. Тартуск. ун-та, вып. 102 (1961),

53. А а ренд Е., Лепик Ю., Лухт Л., Большие прогибы гибкой круглой упругопластической пластинки, свободно опертой по контуру, Уч. зап. Тартуск. унта, вып. 102 (1961).

54. Н игул У., Линейные уравнения динамики упругой круговой цилиндрической оболочки, свободные от гипотез, Тр. ТПИ, А, № 176 (1960).

55. Н и гул У., Асимптотическая теория статики и динамики упругих круговых цилиндрических оболочек, ПММ, 26, вып. 5 (1962).

56. Н и гул У., О применении символического метода А. И. Лурье к анализу напряженных состояний и двумерных теорий упругих плит, ПММ, 27, вып. 3 (1963).

57. Н и гу У,, О приближенном учете краевых эффектов типа Сен-Венана в краевых задачах статики и плит, ПММ, 28, вып. 1 (1964).

58. А й нола Л., Об уточненных теориях пластинок типа Рейсснера, Тр. Всесоюзн. конф. по теории пластин и оболочек, Ереван, 1962.

59. Оллик К., Об осесимметрических колебаниях кругоцилиндрических тонкостенных оболочек, Тр. ТПИ, А, № 147 (1958).

60. Поверус Л., Р я я м т Р., Малые неосесимметричные собственные колебания упругих тонких конических и цилиндрических оболочек, Тр. ТПИ, А, № 147 (1958).

61. Ни гул У., Об общих формах колебания круговой замкнутой цилиндрической оболочки, Тр. ТПИ, А, № 147 (1958).

62. Н и гул У., Некоторые результаты исследования уравнений собственных колебаний упругой кругоцилиндрической оболочкн, Тр. ТПИ, А, № 171 (1960).

63. Алум я э Н., О фундаментальной системе интегралов уравнения малых осесимметричных колебаний упругой конической оболочки вращения, Изв. АН ЭССР. Сер. техн. и физ.-матем. наук, 9, № 1 (1960).

64. Вей гель И., М янниль А., Ор Г Э., Малые установившиеся осесимметрические колебания конической оболочки вращения, Изв. АН ЭССР. Сер. техн. и физ.-матем. наук, 9, № 1 (1960).

65. А й нол а Л., К методам исследования колебаний упругих пластинок, Инженерный журнал, 3, № 2 (1963).

66. Н и уул У., Колебание кругоцилиндрической упругой оболочки, вызванное действием сосредоточенного импульса, Тр. ТПИ, А, № 171 (1960).

67. А лум яэ Н., О применимости метода расчленения напряженного состояния при решении осесимметрических задач динамики замкнутой цилиндрической оболочки, Изв. АН ЭССР. Сер. физ.-матем. и техн. наук, 10, № 3 (1961).

68. Алумяэ Н., Пов ерус. Л., Переходный процесс упругой деформации в замкнутой кругоцилиндрической оболочке при неосесимметрической краевой нагрузке, Изв. АН ЭССР. Сер. физ.-матем. и техн. наук, 12, № 1 (1963).

69. Т юм а нок А., Об осесимметричном неустановившемся движении безмоментной круговой цилиндрической оболочки под действием движущейся нагрузки, Изв. АН СССР. ОТН. Мех. и машиностр., № 4 (1964).

70. Т юм анок А., Неустановившееся осесимметричное колебание цилиндрической оболочки, возбуждаемое подвижной нагрузкой, Изв. АН ЭССР. Сер. физ.матем. и техн, наук, 14, № 3 (1965).

71. Ни гул У., Асимптотическая теория статики и динамики упругих круговых цилиндрических оболочек и анализ точности различных вариантов теории Кирхгоффа-Лява. Всесоюзн. конф. по теории оболочек и пластин, 1962, Ереван, 1964 .

72. Нигул У., О применении символического метода А. И. Лурье в трехмерной теорни динамики упругих плит, Изв. АН ЭССР. Сер. физ.-матем. и техн. наук, 12, № 3 (1963). 
73. Нигул У., О корнях уравнения Лэмба для деформации плиты, антисимметричной относительно срединной поверхности, Изв. АН ЭССР. Сер. физ.-матем. и техн. наук, 12, № 3 (1963).

74. М янниль А., Н и гул У,, О напряженных состояниях упругой плиты при распространении синусоидальных волн изгиба, Изв. АН ЭССР. Сер. физ.-матем. и техн. наук, 12, № 3 (1963).

75. Нигул У., Применение трехмерной теории упругости к анализу волнового процесса изгиба полубесконечной плиты при кратковременно действующей краевой нагрузке, ПММ, 27, вып. 6 (1963).

76. Нигул У., Переходные волновые процессы деформации в упругих плитах конечных размеров, Тр. V Всесоюзн. конф. по теории пластин и оболочек, M., 1965. (В печати).

77. Векслер Н., М янниль А., Нигул У., Применение метода сеток в теории типа Тимошенко для исследования переходных волновых процессов деформации плит конечных размеров, ПМ, 1965. (В печати).

78. Векслер Н., М янниль.А., Нигул У., Из опыта применения усовершенствованного варианта метода сеток к анализу переходных волновых процессов в плитах и оболочках, Тр. V Всесоюзн. конференции по теории оболочек и пластин, М., 1965. (В печати).

79. Векслер Н., Ни гул У., К применению теории типа Тимошенко при осесимметричном волновом процессе деформации сферической оболочки, Изв. АН СССР, Механика, № 6 (1965). (В печати).

80. А йнола Л., О вариационной задаче Кастильяно динамики нелинейной теории упругости, Изв. АН ЭССР. Сер. физ.-матем. и техн, наук, 10, № 1 (1961).

81. Айнола Л., Об одном вариационном методе приближенного решения дифференциальных уравнений с частными производными, Изв. АН ЭССР. Сер. физ.матем. и техн. наук, 11, № 3 (1962).

82. Айнола Л., О расчетных моделях упругих пластинок для динамических задач, Изв. АН ЭССР. Сер. физ.-матем. и техн. наук, 12, № 1 (1963).

83. Айнола Л., Н и г у У., Волновые процессы деформации упругих плит и оболочек, Изв. АН ЭССР. Сер. физ.-матем. и техн. наук, 14, № 1 (1965).

84. А бен Х., О применении метода фотоупругости для исследования пластинок, Изв. АН ЭССР. Сер. техн, и физ.-матем. наук, 6, № 1 (1957).

85. А бе н Х., С а к с Э., Оптические явления при просвечивании оболочек. Поляризационно-оптический метод исследования напряжений (Труды конференции), Изд. ЛГУ $(1960)$.

86. А бен Х., К применению фотоупругих покрытий при исследовании оболочек, Изв. АН СССР. ОТН. Механика и машиностр., № 6 (1964).

87. Абен X., Учет вращения квазиглавных напряжений при исследовании цилиндрических оболочек методом фотоупругости, Изв. АН СССР, Механика, № 4 (1965). (В печати).

88. Лепик Ю., Равновесие упруго-пластических и жестко-пластических пластин н оболочек, Инженерный журнал АН СССР, 4, № 3 (1964).

Таллинский политехнический институт

\section{Поступила в редакцию} 23/III 1965 